\title{
COMPOUND DORSAL GANGLION WITH RICE BODIES
}

\section{T. Venkateshwar Rao${ }^{1}$, K. Venkata Swamy², J. Venkateshwarlu³, D. Prasad Reddy ${ }^{4}$, Shivanshu Mittal ${ }^{5}$}

\section{HOW TO CITE THIS ARTICLE:}

T. Venkateshwar Rao, K. Venkata Swamy, J. Venkateshwarlu, D. Prasad Reddy, Shivanshu Mittal. "Compound Dorsal Ganglion with Rice Bodies". Journal of Evolution of Medical and Dental Sciences 2015; Vol. 4, Issue 37, May 07; Page: 6542-6545, DOI: $10.14260 /$ jemds/2015/948

ABSTRACT: BACKGROUND: Tuberculosis has decreased persistently since the introduction of antituberculous chemotherapy. However there are reports in recent literature indicating that rate of tuberculosis is increasing. ${ }^{1}$ Musculo skeletal tuberculosis occurs in approximately 1-3\% of tuberculosis patients. ${ }^{2}$ Tuberculosis of soft tissue such as tenosynovial sheath or bursa is rare. ${ }^{3}$ We are presenting a rare case of compound dorsal ganglion which is accompanied by multiple rice body formation without co existing active bone and joint tuberculosis. OBJECTIVE: to describe history clinical and radiologic presentation of compound dorsal ganglion and management. METHODS: Detailed history, physical examination and investigations. CONCLUSION: We report a unique case of compound dorsal ganglion with rice bodies formation in absence of any other concomitant focus of tuberculous infection, managed with excision biopsy and anti - tuberculous regimen.

KEYWORDS: mycobacterium infections, tuberculosis, ganglion, granuloma, rice bodies.

INTRODUCTION: Rice body formation is commonly observed in the joint and tendon sheaths among patients with rheumatoid arthritis, however only a few cases with rice bodies of tubercular origin have been mentioned in the literature.

Tuberculosis of the bone and joint occurs in approximately $1 \%$ to $3 \%$ of patients with tuberculosis. ${ }^{2,1}$ The most common type is spondylolitis which accounts for $50 \%$ of all cases. ${ }^{4}$ followed by Peripheral arthritis and osteomyelitis. Involvement of extensor and flexor tendons may result.[5] Totally, tenosynovitis and bursitis account for approximately $1 \%$.

Both primary tuberculous teno synovitis and bursitis are rare conditions. ${ }^{6,3}$

CASE REPORT: A 70 yrs male patient presented with painless swelling over the dorsum of his right wrist joint since 1 year. Patient noticed the swelling 1 year back, which initially was of lemon size over the dorsum of his right wrist, gradually increased and attained the present size. On physical examination there was a single $8 \times 4 \mathrm{~cm}$ dumbbell shaped mass, which appeared to be two swellings but were contiguous on palpation. No local rise of temperature and no tenderness over the swelling. surface was smooth and the borders were well defined. Skin was pinchable and the mass was freely mobile in transverse axis. Swelling was soft and cystic with fluctuation positive, transillumination negative. No restriction of range of movements. No other joints involved. Regional lymph nodes were not palpable.

No history s/o pulmonary koch's such as chronic cough, constitutional symptoms.

No history of trauma. No history of contact with tuberculosis.

Investigations revealed the wbc count was 8,500/cmm. With lymphocytes being $29 \%$. Erythrocyte sedimentation rate was $10 \mathrm{~mm}$, c reactive protein concentration level normal.

Radiography was normal except for soft tissue swelling. Chest radiography did not show any evidence of primary lesion.

USG of the swelling was suggestive of what appeared to be a ganglion cyst. 


\section{CASE REPORT}

FNAC of the mass revealed few scattered oval cells with abundant pink cytoplasm against bluish mucoid background, suggestive of ganglion.

Patient underwent wide excision biopsy of the expected diagnosis of the ganglion cyst. There were a few soft tissue adhesions and the mass was attached to the extensor tendons under the extensor retinaculum but it did not appear to have any extension deep into the wrist joint. The retinaculum was incised open. The mass was excised along with the thickened tenosynovium. Gross specimen findings revealed lobulated mass with thick white membrane. On cut sections, there were rice bodies filled inside the mass. Rice bodies macroscopically resembled shiny white rice grains, size consistency and shape varied and more than half of them being in between 2 to $8 \mathrm{~mm}$ length.

Histopathological examination revealed well defined granulomatous areas showing collections of epitheloid cells, Langerhans Giant Cells, and lymphoid cells with adjoining eosinophilic acellular areas.

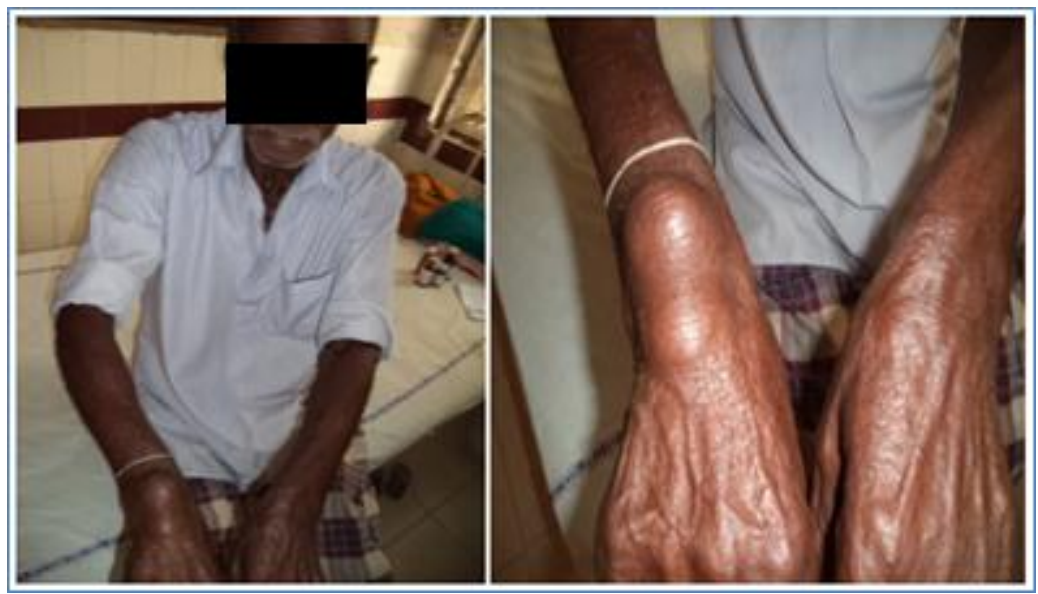

\section{Clinical photos showing the site and the appearance of the swelling}

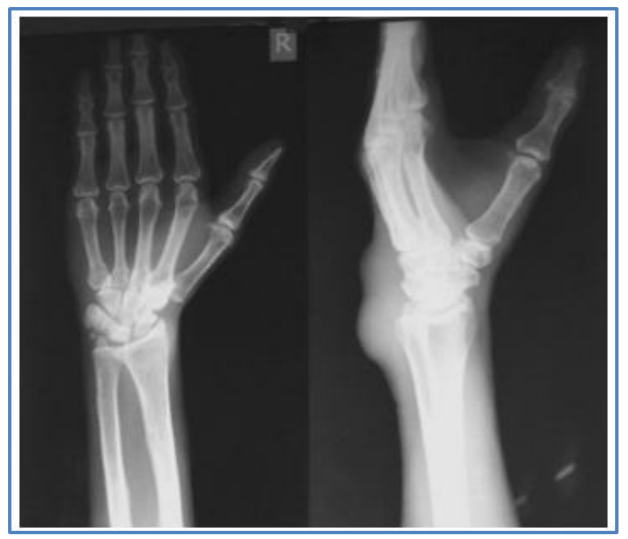

$X$ ray showing a soft tissue shadow Without any bone or joint involvement

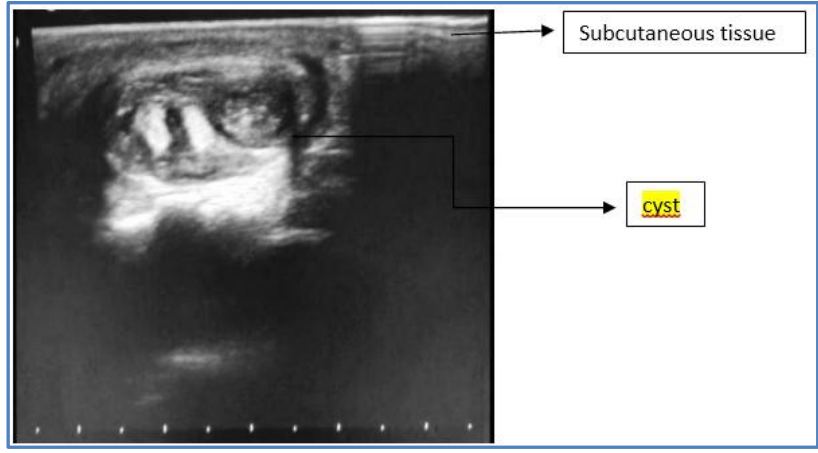

USG showing the cystic lesion in the subcutaneous tissue 


\section{CASE REPORT}

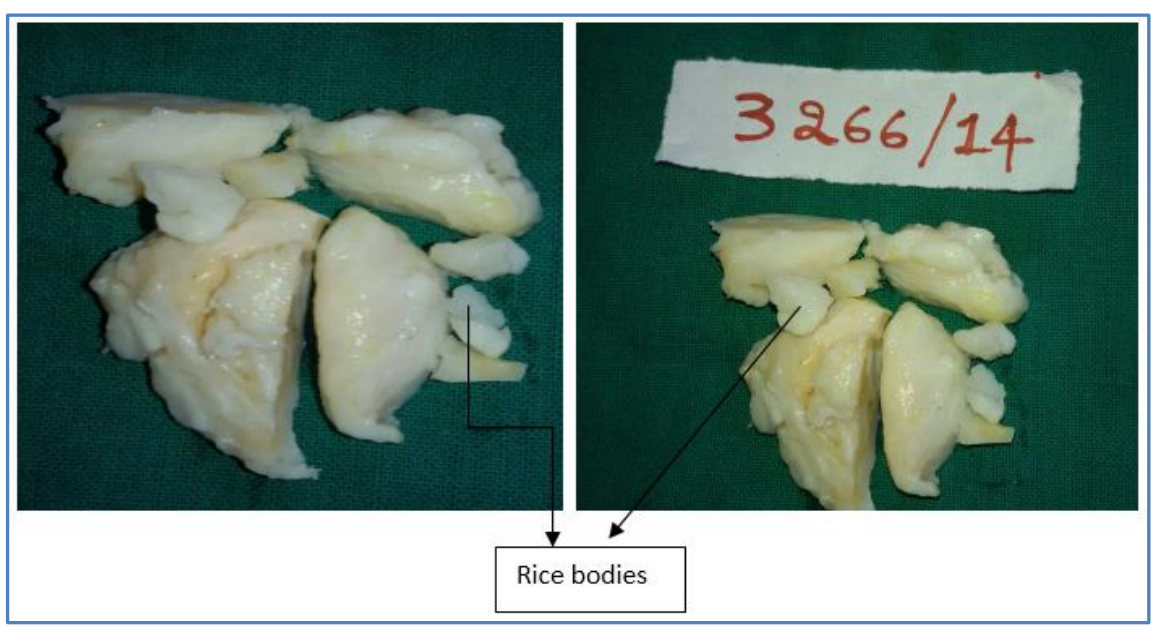

Gross specimen picture showing rice bodies

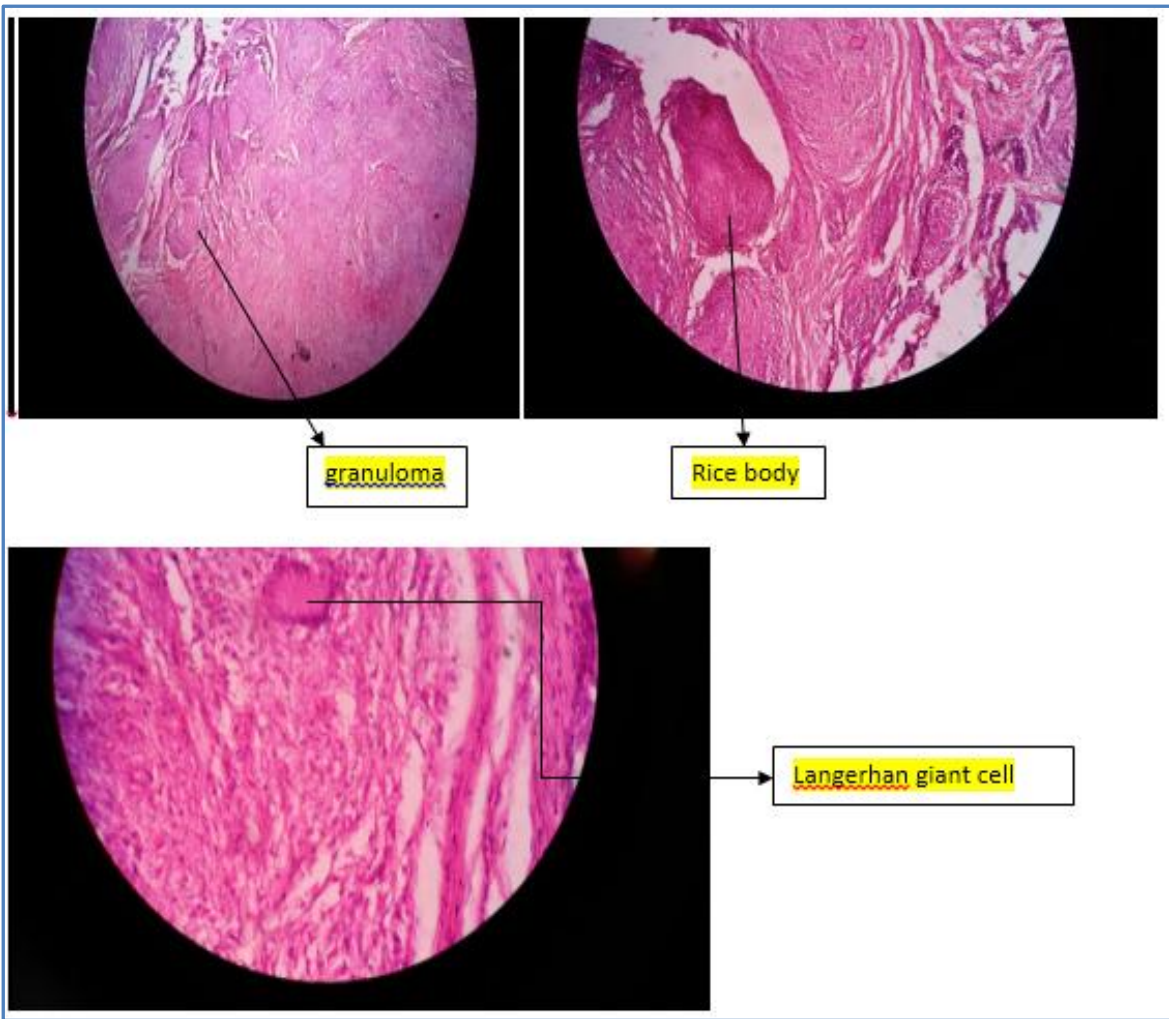

Light Microscopic pictures showing granuloma, rice body, giant cell

DISCUSSION: Primary tuberculous tenosynovitis and bursitis are rare conditions. ${ }^{6,3}$ Rice bodies occurring in joints due to TB was first described in 1895.7 These are a common finding in rheumatoid arthritis, SLE, seronegative arthritis, tuberculosis, atypical mycobacterial infections and non-specific arthritis. ${ }^{7}$ Etiopathogenesis of tuberculous tenosynovitis may be either due to direct inoculation or due to hematogenous spread., ${ }^{3,2}$ However the later doesn't seem to be a source in this case as there were not even healed TB lesions. 
The cause of rice body formation remains obscure. Some authors proposed a synovial origin with microinfarction ${ }^{8}$ leading to synovial sloughing and subsequent encasement by fibrin derived from synovial fluid. Others thought that earliest rice bodies are formed denovo 4 in synovial fluid independently of synovial elements and that their presence is due to progressive enlargement of fibronectin/fibrin aggregates 2 .

CONCLUSION: We report a unique case of tuberculous tenosynovitis with rice body formation in absence of any other concomitant focus of tuberculous infection, managed with wide excision and category I anti -tuberculous regimen according to DOTS (Directly observed treatment short course).

\section{REFERENCES:}

1. Supriya Mannepalli et al. Mycobacterium tuberculosis osteomyelitis in a patient with human immunodeficiency virus/acquired immunodeficiency syndrome (HIV/AIDS): a case report. Cases Journal 2010, 3:67 doi: 10.1186/1757-1626-3-67.

2. Sanders CJ, Schucany WG. Tuberculous tenosynovitis. Proceedings (Baylor University Medical Center). 2008; 21(1):71-72.

3. Hitesh lall et al. Tuberculous extensor tenosynovitis of the wrist with extensor pollicis longus rupture: a case report Journal of Medical Case Reports 2009, 3:142. doi: 10.1186/1752-1947-3-142.

4. Sankaran B. Tuberculosis of Bones \& Joints; Ind. J. Tub., 1993, 40, 109.

5. Campbell's operativeorthopaedics12th edition page no: 781 .

6. Tuli S.M. Tuberculosis of skeletal system 4th edition. Page no: 187-190, 158.

7. Shahaji Chavan, Shyamsunder Shambhu Sable, Sachin Tekade, and Prashant Punia, "Tuberculous Tenosynovitis Presenting as Ganglion of Wrist," Case Reports in Surgery, vol. 2012, Article ID 143921, 3 pages, 2012. doi:10.1155/2012/143921.

8. Hiroyuki Nagasawa, et al Tenosynovitis with rice body formation in a non-tuberculosis patient: A case report Ups J Med Sci. 2009 September; 114(3): 184-188.

\section{AUTHORS:}

1. T. Venkateshwar Rao

2. K. Venkata Swamy

3. J. Venkateshwarlu

4. D. Prasad Reddy

5. Shivanshu Mittal

\section{PARTICULARS OF CONTRIBUTORS:}

1. Professor \& HOD, Department of Orthopaedics, M. G. M. H/K. M. C. Warangal.

2. Assistant Professor, Department of Orthopaedics, M. G. M. H/K. M. C. Warangal.

FINANCIAL OR OTHER COMPETING INTERESTS: None
3. Associate Professor, Department of Orthopaedics, M. G. M. H/K. M. C. Warangal.

4. Tutor, Department of Orthopaedics, M. G. M. H/K. M. C. Warangal.

5. Post Graduate, Department of Orthopaedics, M. G. M. H/K. M. C. Warangal.

NAME ADDRESS EMAIL ID OF THE CORRESPONDING AUTHOR:

Dr. K. Venkata Swamy, \# 25-7-186, Vishnupuri, Kazipet, Warangal-506003, Telangana.

E-mail: drlathavenkat@gmail.com

Date of Submission: 06/04/2015.

Date of Peer Review: 07/04/2015.

Date of Acceptance: 28/04/2015.

Date of Publishing: 07/05/2015. 